\title{
Critical analysis of the achievements of the global millennium development goals and new approaches to sustainable development management
}

\author{
Anzhela Lelechenko ${ }^{1 *}$, Olga Lebedinska ${ }^{1}$, Sergii Somin ${ }^{2}$ and Iryna Dynnyk ${ }^{3}$ \\ ${ }^{1}$ Department of Regional Governance, Local Self-Government and Urban Management, National \\ Academy for Public Administration under the President of Ukraine, Kyiv, 03057, Ukraine. \\ ${ }^{2}$ Chief Researcher of the Department of Legal and Anti-corruption Policy, The National Institute for \\ Strategic Studies Kyiv, 01030, Ukraine. \\ ${ }^{3}$ Department of Competitive Selection of Higher Education Applicants, The National Academy for \\ Public Administration under the President of Ukraine, Kyiv, 03057, Ukraine.
}

\begin{abstract}
This article provides a critical analysis of the achievements of human development towards sustainable development in the 17th Global Goals and reveals new approaches to the management of this process. Because these goals are related, the success in achieving one of them affects the success of the entire set of goals. This made it possible to distinguish the most acute globalization problems that have require urgent collective attention and special consolidated mechanisms to solve them. It is necessary to establish a unified global system of data collection on indicators of sustainable development from all countries of the world in order to achieve the fundamental social and economic transformations in 2030. The authors identify a new paradigm for the management of sustainable development in the form of governance in the process of achieving the 17 Global Millennium Goals, which aims to provide making such strategic decisions that would serve global interests, and national efforts are supported by effective interstate cooperation through diplomacy and crisis prevention. The researchers generalized the main challenges and suggested to identify the relationships between existing problems of human activity more effectively, adopting an integrated approach and increasing significantly investments in poverty alleviation, inequality and climate change.
\end{abstract}

\section{Introduction}

Assessment of the Global Millennium Goals' level of achievement and new approaches to sustainable development management is an extremely important and difficult task. Existing methods and tools for achieving sustainable development goals are aimed at finding new, more effective ways and mechanisms for support the livelihood of mankind,

\footnotetext{
* Corresponding author: lelechangel@ukr.net
} 
and are not only an applied task, but also in a certain way determine the priorities for the development of the modern world scientific idea, especially in the humanitarian sphere.

Effective public policies around the world should address economic, social issues, and environmental issues. To prevent these negative manifestations, the Sustainable Development Goals require the implementation of governance mechanisms that define global priorities and aspirations for 2030 .

Based on the studies, it is necessary to develop an optimal model of sustainable government administration that will enable governments around the world, to set national plans of action, policies and initiatives that reflect the different realities and opportunities that characterize these countries, based on the Millennium Development Goals, and to define or adapt their course on sustainable development management based on common indicators and priorities. In our opinion, public governments in all countries of the world need to create the appropriate national conditions for achieving the Millennium Development Goals by conducting an objective analysis of achievements, positive experiences and development risks for certain goals. It will help identify areas of "unfinished deals" and new challenges that arise in the development of the world community. However, despite the organizational, administrative, scientific, and communication activities undertaken, issues of achievement of the Global Millennium Goals and public authorities new approaches to manage sustainable development require critical analysis.

\section{Method}

Research of various aspects of determining and understanding sustainable development's essence, its components are carried out of many institutions. However, until now, issues related to the methodology for the development and implementation of critical analysis to achieve the Global Millennium Goals as part of managing the sustainable development of Ukraine, as well as other countries of the world in the face of modern challenges and threats remain insufficiently developed.

The methodological basis of this study is scientific. It is based on unique knowledge methods, conceptual rules of modern socio-environmental-economic theory, research of reports of the World Bank and other international institutions $[6,8,10,11]$ and others.

A critical analysis of the achievement of the Global Millennium Goals, which involved the development of new approaches to sustainable government administration, aimed at creating a comprehensive platform to stimulate an understanding of the priorities and common goal in all areas of socio-environmental and economic development of countries were conducted in the study, as well as a more effective partnership between governments and civil society organizations around the world, is particularly urgent.

Using the method of prediction, the effectiveness of public policy in regulating and predicting rates of sustainable development in many countries was determined. The analysis made it possible to propose an author's vision for developing and implementing a global methodology for assessing the state of sustainable development in many countries.

This study used methods of system approach and system analysis of the 17 Goals, which together allowed reaching an objective assessment of the general state of sustainable development of the world's states. It has demonstrated a variable approach (sometimes ineffective) and the necessity to improve mechanisms to eliminate all significant obstacles to every human being's decent life in any society. Opinion of this study, it is possible to solve the problems of realization of the Millennium Development Goals by combining the effective public policy and mechanisms of integrated assessment of the overall state of sustainability of a particular state and society in the field of sustainable development. 


\section{Results and discussion}

The presence of human civilization is characterized by the emergence and growth of extremely acute globalization problems. Which have covered almost all spheres of life and have gone beyond the borders of states and continents, affecting the vital interests of every world's inhabitant, regardless of race, faith, citizenship, or property status.

According to the authoritative global think tank at the United Nations, The Millennium Project (MP Node), humanity has already reached the limit where it is urgently necessary to change and improve thinking about the future fundamentally and make this thinking accessible and comprehensive through various media, in order to accumulate wisdom about the future for making better decisions today [1]. First of all in analyzing the current generally accepted principles for the development of human civilization, it should be noted, that in 15 years the Millennium Development Goals have been the driving force for reducing income poverty, providing extreme needed access to water and adequate sanitation, reducing child mortality, as well as substantial improvement of the maternal health. They have also created a momentum to the global movement for free primary education, encouraging countries to invest in future generations. The Millennium Development Goals have made tangible progress in the struggle with HIV/AIDS and other previously incurable diseases, in particular malaria and tuberculosis. The main advances (compared to 1990) were: more than 1 billion people were saved from extreme poverty; child mortality and the number of children who do not go to school decreased by more than half; HIV/AIDS cases have fallen by almost 40\% (Global Sustainable Development Goals: 2015-2030, 2020).

The United Nations Annual Sustainable Development Goals Report, 2019 provides a detailed overview of the efforts of the world community over the past four years to achieve sustainable development goals, highlighting areas in which positive developments have been achieved, as well as problems that still need to be worked on so that no one is left behind. The report noted progress in some areas, including reducing extreme poverty, continuous immunization, reducing child mortality, and increasing people's access to electricity. But at the same time, it is noted that global measures did not affect the poorest people and countries, forcing them to suffer the most. According to UN Secretary-General Antonio Guterres, "It is clear that a deeper, faster and more ambitious response is needed to carry out social and economic transformations to achieve our goals for 20-30 years" [3].

Key observations of the UN Annual Report include:

- growing inequalities between and within countries of the world require immediate attention and concrete action;

- over half of the world's children cannot read or count, most of them live in South Asia and Sub-Saharan Africa;

- extreme poverty in rural areas is three times higher than in urban areas;

- young people are more affected by unemployment than adults;

- at least half of the world's population does not have access to basic health care, only a quarter of people with severe disabilities receive appropriate social assistance and payments;

- women and girls continue to suffer from systemic inequalities and discrimination, feeling significant obstacles to equality [3].

While the quantity of people living in extreme poverty has fallen from 36 percent (in 1990) to 8.6 percent (in 2018), the rate of poverty reduction is beginning to slow down, especially in the context of the increasing risks posed by persistent pandemics, continuous armed conflict, and natural anomalies. The danger of global hunger is growing after a rather long decline. The natural environment continues to deteriorate at an alarming rate: the ocean level is rising, its acidification is accelerating, and according to forecasts by 2100 it 
will increase by $100-150 \%$. One million species of plants and animals are on the verge of extinction, and land degradation is steadily continuing.

In June 2019, a team of independent experts from the SDSN Secretariat and The Bertelsmann Stiftung prepared a report on sustainable development in 2019, "Transforming for Sustainable Development Goals," which presents the Sustainable Development Goals Achievement Index (SDG Index), information panels for all UN member states, as well as a framework for achieving sustainable development goals. To date, this report remains the only well-known authoritative comparative analysis that compares the achievements of leading countries and developing countries in the context of sustainable development [6].

According to these internationally recognized experts, none of the 193 countries that have agreed to implement the $17 \mathrm{UN}$ sustainable development goals will objectively be able to do this on time. At the same time, industrialized countries play a rather mixed role in achieving the global Sustainable Development Goals - on the one hand, they are closest to the Millennium Development Goals, and on the other, the Organization for Economic Cooperation and Development countries contribute to the growth of environmental and economic costs in underdeveloped countries.

The authors are mainly concerned with the agriculture and soil pollution. Such as a quarter of the world's greenhouse gas emissions are from land management, more than $78 \%$ of all countries are in the red zone due to nitrate pollution, and the discrepancy between malnutrition and overproduction of food continues to grow.

According to the SDSN report, the Group of Twenty countries (Major Advanced and Emerging Economies, G20) are fully responsible for about half of the problems on the way to achieving the global goals to finance relevant programs. Only a few G20 club countries met the UN requirement to allocate $0.7 \%$ of GDP to international assistance for sustainable development.

The analysis of the achievements of human development towards sustainable development over the 17 global Goals allows us to highlight the most pressing problems that require urgent collective attention and special mechanisms to solve them or reduce the negative impact on the life of the world community. The world requires building a fundamentally new qualitative model of sustainable development management by developing and implementing a single mechanism for government regulation of this process at the regional, national and global levels. As a result, it will be possible to identify the relationships between existing human problems more effectively, apply an integrated approach and effective mechanisms that will help to give a suite of general standards and feasible objectives for reducing carbon emissions, manage the risks of climate change and natural disasters, and to create a better world after a crisis.

\subsection{Goal 1. Overcoming poverty}

According to expert estimates, despite all the world community's efforts and the unconditional reduction of general extreme poverty, the complete elimination of this shameful phenomenon until 2030 will not be achieved objectively. According to an analysis of the distribution of poor people by region of the world (see figure 1) [6], the global rate of overcoming poverty has slowed significantly compared to the last century. 


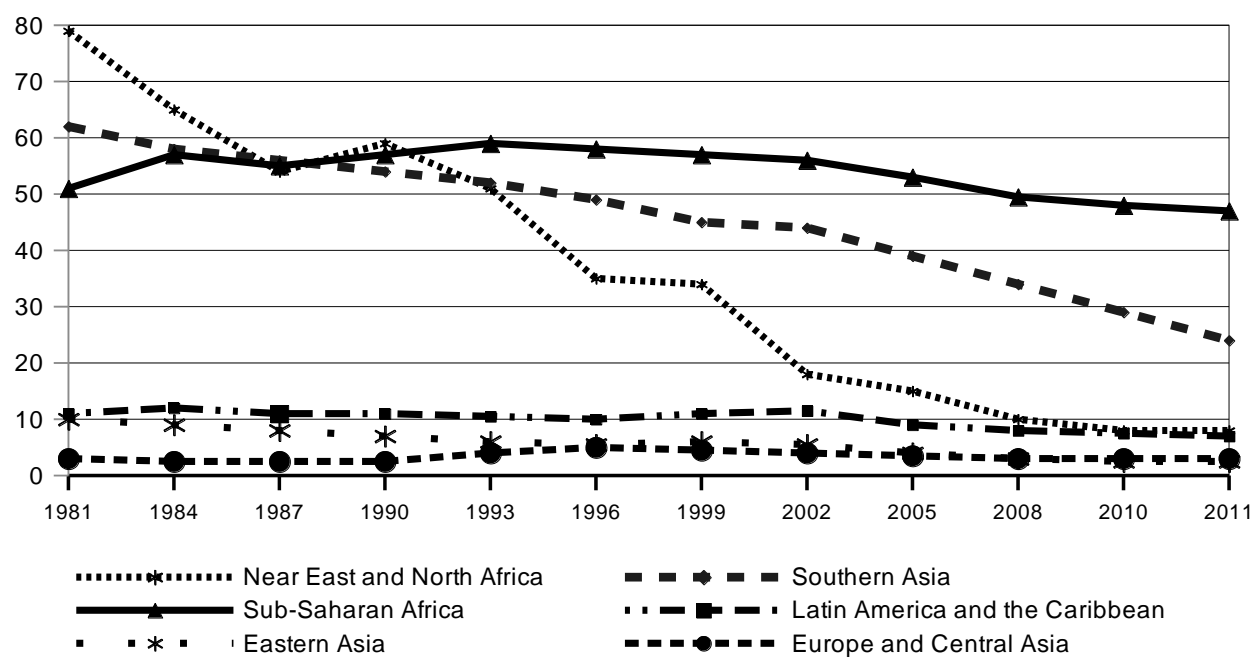

Fig. 1. Trends in the distribution of the poor by region of the world (in\% of the total population of the Earth) [6]

\subsection{Goal 2. Overcoming hunger, agricultural development}

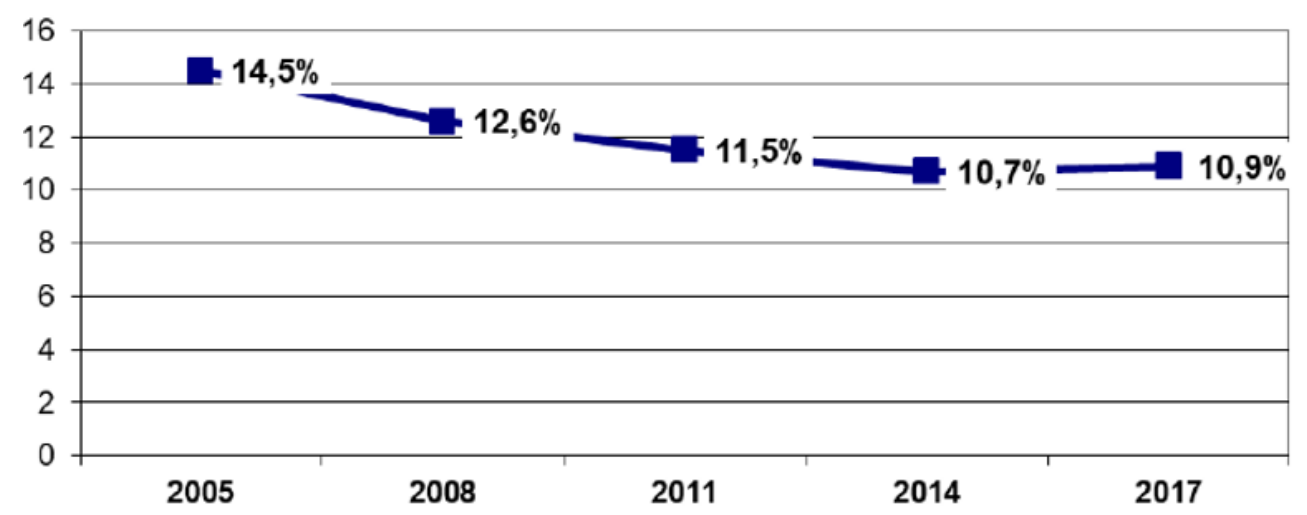

Fig. 2. Percentage of the world's undernourished population, 2005-2017 (in \%) [3]

As shown in Figure 2 [3], despite quite long progress in the fight against malnutrition, starting in 2014, the number of starving people on the planet is steadily growing. The hunger situation in Sub-Saharan Africa has deteriorated, particularly (from 195 million in 2014 to 237 million in 2017). In 2018, 149 million children under the age of 5 suffered from chronic malnutrition ( $22 \%$ of children in the world). Three-quarters of them lived in South Asia (39\%) and in Sub-Saharan Africa (36\%). Reducing their number to 83 million, as indicated in the global Sustainable Development Goals until 2030, is unlikely to be reached. Besides, ensuring full nutrition on the planet is also associated with food quality. Globally, as of 2016, the problem of overweight, and then the lack of full nutrition, affected $20.6 \%$ of children aged 5 to 9 years (131 million people), $17.3 \%$ of adolescents (207 million people), and $38.9 \%$ of adults ( 2 billion people).

According to our estimates, the global sustainable development goal of eliminating hunger until 2030. Ensuring food security and quality improvement in nutrition will not only not be achieved, but on the contrary, the situation in this area can deteriorate 
significantly compared to 2015 .

\subsection{Goal 3. Good health and well-being}

Statistics show that, during recent years, significant improvements have been achieved in the health of millions of people around the world. Maternal and infant mortality have been reduced, life time has gradually increased, and progress has been consolidated in the fight against some infectious diseases.

However, as the situation with the development of the pandemic COVID-19 and the results of the fight against malaria and tuberculosis shows, we have not yet achieved a comprehensive healthy lifestyle and well-being at any age for all. Too many people continue to die due to the lack of qualified health workers and the ability to guarantee basic medical care, including immunization. Over half of the world's inhabitants have no access to basic health care at all. Even in developed countries, the occurrence of a person's emergency health problems can put him on the brink of bankruptcy. Now in almost $40 \%$ of the world's countries, 10 thousand people account for less than 10 doctors, and in about $58 \%$ of the countries for 10 thousand people - less than 40 nurses and midwives. At the same time, there is a significantly uneven distribution of health workers among different countries, as well as within countries themselves.

People must do many things towards developing an all-embracing the system of medical treatment - to ensure sustained and adequate health-care funding, to ease the growing burden of infectious diseases and mental disorders, and to address issues, related to antimicrobial resistance and environmental factors that severely affect human health (air pollution, non-compliance with water and sanitation safety requirements, unhealthy food, etc.). It is estimated that in order to provide adequate health services for all inhabitants of the planet until 2030, it is necessary to additionally train and employ about 18 million medical workers, which is almost impossible to realize.

\subsection{Goal 4. Quality education}

One of the Millennium Goals is to provide comprehensive and equitable quality education. So it can promote lifelong learning as an integral part of vertical socio-economic mobility and essential prerequisites for overcoming poverty.

Despite years of constant primary school-age enrolment rates increase, the percentage of children who cannot read and write remains alarmingly high. In 2015, approximately 617 million young and middle-aged children and adolescents (55\% of their number in the world) did not even have the minimal functional ability to read and count (see figure 3) [3].

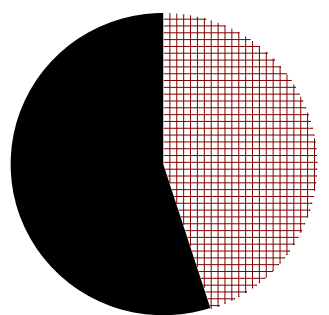

\footnotetext{
$55 \%$ of children in the world cannot read and write

$45 \%$ can read and write
}

Fig. 3. The proportion of children and adolescents in the world who have not reached the minimum level of functional ability to read and count, 2015 (in \%) [3]

Approximately two-thirds of them had attended school in the past but had left school for various reasons. The proportion of such children is highest in Sub-Saharan Africa, where 88 percent of children (202 million) do not have functional reading skills, and 84 percent (193 
million) can't count. In Central and South Asia, 81 percent of children (241 million) cannot read, and 76 percent (228 million) cannot count. The global crisis of the education system kills the very ability of certain backward countries (or people) to free themselves from poverty and begin to develop. It has a significantly negative impact on the rest of the countries economic future, significantly complicating the competition in the world market due to the insufficient level of skills of their own labor resources.

Achieving quality education as a global Millennium Development Goal requires substantial increases in funding and targeted public policies in this area at the national and global levels. There are significant doubts that we will be able to ensure a comprehensive and equitable quality education throughout the world, to provide every resident of the planet with the opportunity to increase their educational level throughout life by 2030 .

\subsection{Goal 5. Gender equality}

Despite some advances towards gender equality (a decrease in the number of girls forced into early marriage, an increase in the number of women in parliaments and leadership positions. Such as, reform of individual national legislation to ensure gender equality, etc.), discriminatory laws and social norms, harmful social activities and other forms of violence against women and girls are still quite widespread throughout the world.

Women and girls of the world continue to suffer violence and abuse that degrades human dignity and adversely affects their well-being. Intimate partner violence affects women of all ages and ethnic groups, regardless of their socio-economic status and education level in all countries. According to the latest data from 106 countries, $18 \%$ of women and girls between the ages of 15 and 49 who were ever in an intimate relationship were physically (sexually) abused by a partner.

Moreover, female genital mutilation (FGM) is a blatant violation of the inalienable human rights of nearly 200 million women in 30 countries (half in West Africa), with a medium of one in three girls aged 15 to 19 years being forced into FGM. According to the $\mathrm{UN}$, in almost half the world's countries, women spend an average of three times more time on free housework than men every day. This applies primarily to the care of children, the elderly and the sick, cooking, as well as cleaning in the house.

Gender equality is a serious global problem. The analysis shows, it is unlikely to be fully achieved by 2030 for a variety of objective reasons, especially historical, mental, psychological, and spiritual-religious ones.

\subsection{Goal 6. Clean water and adequate sanitation}

While there has been tangible progress in improving availability of safe pure water and sanitation, almost 3 billion inhabitants (mainly rural) have still problems with washing their hands at home.

In 2016, a third of all educational schools on the planet lacked the basic infrastructure for drinking water, sanitation, and hygiene services. A quarter of all health facilities in the world also lacked basic water services infrastructure, increasing the risk of infection by dangerous diseases for more than 2 billion patients in health facilities. Water demand, especially drinking water, is growing faster than population growth, and already over half of the world's inhabitants experience severe water shortages for at least a month per year. The degree of pollution of most rivers in Asia, Africa, and Latin America is higher at our time than in the nineties of the XX century. Over the past 100 years, about $50-70 \%$ of natural wetlands have disappeared worldwide. $60 \%$ of all countries have not reached the trajectory necessary for the implementation of the global framework project "Integrated Water Resources Management" (IWRM), which includes an appropriate strategy, 
institutions, management, and financing mechanisms, until 2030.

According to the UN estimate, to achieve the global Millennium Goal and ensure global access to drinking water and basic sanitation, this area's progress must now be at least doubled. There is an urgent need to change qualitatively and expand wastewater treatment practices, improve water efficiency significantly, enhance collaboration on transboundary water basins' practical operation, also protect and restore freshwater ecosystems. In the context of the growing global economic crisis and the situation with the development of the COVID-19 pandemic, it will be extremely problematic to do all the tasks before 2030 .

\subsection{Goal 7. Affordable and clean energy}

Experts estimate that there has been tangible progress towards universal access to accessible, reliable, sustainable and modern energy for all. The overall rate of electricity access expansion in the poorest countries has begun to increase, energy efficiency has improved, also there has been a steady increase in the share of electricity produced from renewable sources.

However, 840 million inhabitants of the world (mostly in sub-Saharan Africa) did not have access to electricity as at 2017 . In total, $87 \%$ of people in the world who still do not use electricity live in rural areas. Lack of access to better fuels and technologies is very significant cause of ill health and deterioration of the state of the environment, particularly in low- and middle-income economies. Almost 3 billion people on the planet are forced to use inefficient and highly polluting cooking systems, which in turn leads to the premature death of about 4 million people. With a fairly high degree of probability, it is hoped that we will be able to achieve the global Millennium Development Goal partially and ensure the common access of all earthmen to electricity. Technological progress and the development of affordable, reliable, and low-cost electricity systems will be crucial. But addressing this issue will require additional concerted efforts by all countries, particularly the highly developed countries, to remove key barriers related to the availability, affordability, and reliability of the latest high-efficiency energy sources, as well as the necessary public awareness on this issue.

\subsection{Goal 8. Decent work and economic growth}

The current situation of the impact of the pandemic COVID-19 and the possible deployment of a new global economic crisis against this background. It does not allow for sufficiently accurate global forecasting until 2030 to promote gradual comprehensive and sustainable economic growth, as well as the achievement of employment and decent work for everybody.

However, today we can conclude that we may not be able to achieve the planned targets fully. Especially in the areas of : a significant increase in growth targets of the least developed countries; tangible expansion of employability (particularly for youth); reducing inequality between different regions and age groups; reducing employment informality; as well as ensuring safe and reliable terms of employment for employees until 2030.

Of particular concern is the issue of informal employment, as an attribute of high levels of poverty and an irreducible barrier of providing decent work opportunities for all. It is it that affects extremely negatively the incomes of the population, social protection, industrial safety, health of workers and general working conditions.

According to recent data, the proportion of people who work in informal employment is more than $50 \%$, in almost all developing countries, with the proportion of women exceeding that of men. The persistence of the wage gap between women and men remains a global trend, one of the shouting manifestations of gender inequality. In almost half of the 
world, men's average hourly earnings are $12 \%$ higher than those of women. The median wage difference between men and women exceeded $20 \%$ among managers at all levels, professionals, skilled industrial workers, and complex machine operators.

The objective reasons for this difference include the historical spread of strong society's rules and aspirations regarding functions of women in public, which are enshrined in cultural traditions. Combined with the existing inequalities in women's employment opportunities and their limited access to social protection, these factors perpetuate the stereotype of the original natural income gap between men and women, which threatens the achievement of gender equality by 2030 , but for a long term. Global gains in overcoming unemployment, achieving full and productive employment until 2030 will also be determined by the peculiarities of the situation associated with the consequences of the pandemic COVID-19 and the possible world economic crisis, but existing negative trends in this area should be highlighted.

So, unemployment among young people is traditionally three times higher than that for the adult population all around the world. As of 2018, every fifth young person on the planet did not study, did not work, and did not acquire professional skills. It is significant that girls' fate in this category of youth is twice the number of men. Unemployment rates in North Africa, West Asia, Latin America, and the Caribbean are typically more than 2.5 times higher than in Central and South Asia.

\subsection{Goal 9. Industry, innovation and infrastructure}

Continuous industrialization, combined with innovation and the development of appropriate infrastructure, creates new jobs and revenue generation, which is a crucial in implementing innovative technologies, stimulating global commerce, and creating conditions for the efficient utilization of resources. Despite recent progress, the least developed countries have still a low level of industrialization. The slowdown in growth in the manufacturing industry due to the emergence of new trade and tariff barriers was the global trend in 2018, as well as the complication of investment activities. Labor productivity in industrial production in rich and poor countries is strikingly dissimilar. As shown in Figure 4 [3], manufacturing's per capita value added was only $\$ 114$ in the least developed countries and the US \$4,938 in Europe and North America in 2018.

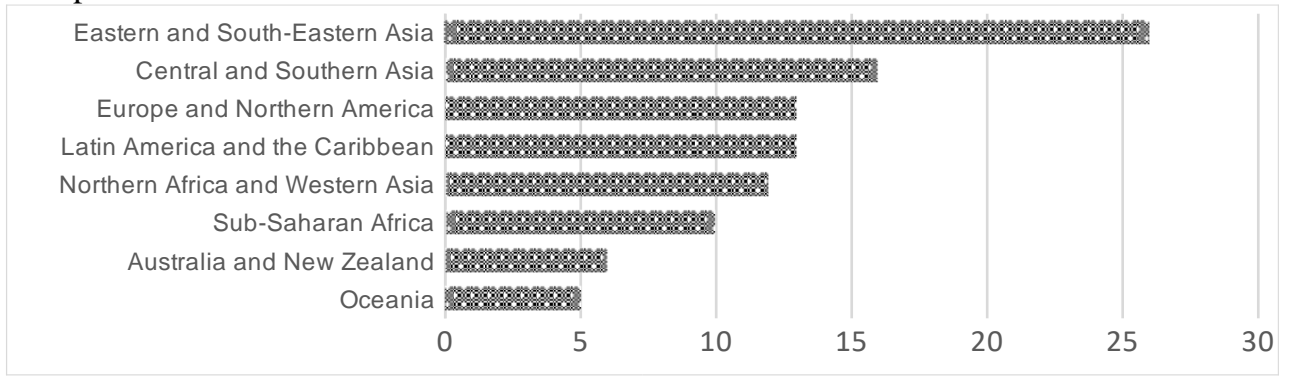

Fig. 4. The share of value added that is created in the manufacturing industry in GDP in different countries of the world, 2018 (in \%) [3]

Small enterprises continue to suffer from a lack of financial services and investment as the main driving force for industrial development in the world's poorest countries. In Latin America and the Caribbean, for example, only slightly more than half of all small enterprises in manufacturing and services use loans and loan facilities, and the share of such enterprises in sub-Saharan Africa is only $20.7 \%$. Particularly stark differences in growth rates in various regions of the world are observed in high-tech manufacturing sectors. So, 
sectors with an above-average level of technic ability accounted for more than $47 \%$ of total value added in the countries of East and Southeast Asia, in Europe, North America in 2016. But in Oceania, these figures were only 1.9\% (with the exception of Australia and New Zealand).

Moreover, small enterprises' profitability in the manufacturing industry with an aboveaverage level of technicality decreased steadily in sub-Saharan Africa between 2000 and 2016. It is too early to talk about the possibility of achieving the global Goal of all-over industrialization, innovation, and infrastructure shifts, primarily due to the significant differentiation of these indicators between different countries and regions of the world.

\subsection{Goal 10. Reducing inequalities within and among countries}

In our assessment, progress towards the global Millennium Development Goal -achieving equality - is highly mixed and contradictory. For example, the United Nations estimates that most countries in the world have experienced a relatively low growth performance of the poorest $40 \%$ of the population, which accounts for only $25 \%$ of the world's total income. But at the same time, the growth in incomes of $1 \%$ of the world's most well-off population (which is more than 2 times ahead of the same growth of $50 \%$ of Earth's inhabitants) remains the global trend, and there is practically no growth in incomes for people who are between these categories (in particular in the USA and Europe). In addition, inequality widely varies across regions of the world.

So, the share of national income accounted for $10 \%$ of people with the highest earnings was: in Europe - 37\%, in China - 41\%, in the Russian Federation - 46\%, in the USA and Canada - 47\%, in sub-Saharan Africa, Brazil and India - about 55\%, and in the Middle East - 61\% (the highest level of inequality in the world) in 2016. All this leads to the fact that inequality in the world as a whole does not decrease, but instead grows.

In North America, China, India, and Russia - at quite a fast pace. In Europe, it grows relatively slow [7].

It is our deep conviction that the fight against inequality cannot be considered only in terms of increasing the incomes of the poorest. According to statistics, income inequality does not fully correlate with the level of development of national economies and can be observed in both poor and rich countries.

Reducing inequalities within and between countries is primarily a moral and ethical problem, which is related primarily to the awareness by power elites of the need to introduce the principle of social equity for all, without distinction as to race, faith, or place of residence. The process of reducing inequality between and within countries should have indicators of a two-way road - when the share of income of the poor increases and the share of the richest in Gross National Income (GNI) decreases gradually at the same time.

The creation of a global register of financial assets that would enable the rapid identification of their owners, strengthen the fight against tax evasion, money laundering, and the widespread implementation of progressive taxation is far from a complete list of measures that will reduce inequality in practice. In general, all government support to the middle class by ensuring equal access to education, cultural heritage, innovation, and wellpaid jobs will contribute to other sustainable development goals to 2030 .

\subsection{Goal 11. Sustainable development of cities and communities}

Despite measures taken by almost all countries of the world to ensure the openness, security, viability, and environmental sustainability of their cities (human settlements), it will not be possible to achieve this global Millennium Goal by 2030 objectively. For example, the number of people on the planet living in slums has grown to more than 1 
billion over the past five years. The results of the analysis, shown in Figure 5 [3], reports that 80 percent of the world's urban population living in slums and informal settlements in 2018 were in East and North-East Asia (370 million), North-Saharan Africa (238 million), and Central and South Asia (227 million).

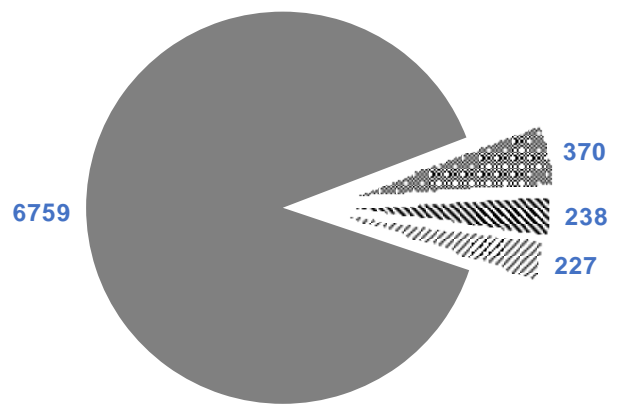

\author{
East and Northeast Asia \\ s Sub-Saharan Africa \\ " Central and South Asia \\ people with decent hous- \\ ing
}

Fig. 5. The urban population of the Earth, who lived in slums and informal settlements in 2018 (in million person) [3]

The growth of slum dwellers is influenced not only by growing urbanization, but also by the growth of the Earth's population, which significantly exceeds the pace of construction of new low-cost housing. According to expert estimates, additionally, 3 billion people will need basic inexpensive accommodation by 2030. According to data from 227 cities located in 78 countries, only $53 \%$ of urban residents had convenient access to public transport stops (within a radius of $500 \mathrm{~m}$ ), or railway/ferry stations (within a radius of 1000 $\mathrm{m}$ ) in 2018. Only 18 percent of the population had convenient access to public transport in Sub-Saharan Africa. In total, 2 billion people in the world were not covered by waste collection systems, and 3 billion did not have access to equipped waste collection systems. But the total volume of global waste is expected to double (from 2 billion to about 4 billion metric tons) by 2050 .

In low- and middle-income economies, the vast majority of urban solid waste facilities are in the form of open dumps and contribute to air, water, and soil pollution, and they also suffer from greenhouse gas emissions, in particular methane.

As of 2016, nine out of ten residents of cities on the planet breathed polluted air that did not meet the WHO's requirements, with half of them breathing air with a level of pollution twice the norm. The air quality of more than a half of the Earth`s population has generally deteriorated over the past decade.

And in low- and middle-income economies, more than $97 \%$ of cities with a population of more than 100 thousand residents did not meet the established air quality parameters. We estimate that the safety and environmental sustainability of the vast majority of cities (human settlements) of the planet will not improve by 2030, but rather will have worse characteristics than now, due to the uncontrolled increase in megacities, the rapid growth of slum dwellers, infrastructural congestion and life support systems (waste collection, water and sanitation systems, road transport systems, etc.).

\title{
3.12. Goal 12. Responsible consumption and production
}

Ensuring the transition to sustainable consumption and production patterns is one of the global Millennium Development Goals and has received considerable attention from the world community. However, on a global scale, we do not reduce, but rather increase, the use of natural resources without significantly increasing the efficiency of the latter's use. 
The volume of waste of human life is steadily growing. About one-third of food is lost or dumped each year, with most of the losses occurring in developed countries. Reducing our resource costs ("Material footprint") is one of the priority tasks of development and humankind's survival in general.

According to the UN methodology, "resource costs" should be understood as the overall quantity of raw materials produced to answer final demand for consumption. This indicator measures the level of environmental pressures arising from the need to sustain economic growth and meet the population's material needs. Global resource costs rose from 43 billion metric tons in 1990 to 54 billion in 2000. and up to 92 billion in 2017 (i.e. $70 \%$ towards 2000 and $113 \%$ - towards 1990).

As the analysis in Figure 6 [8] shows, the growth rate of global resource costs on the planet has significantly outpaced both the growth of the world's population and world production growth since 2000 .

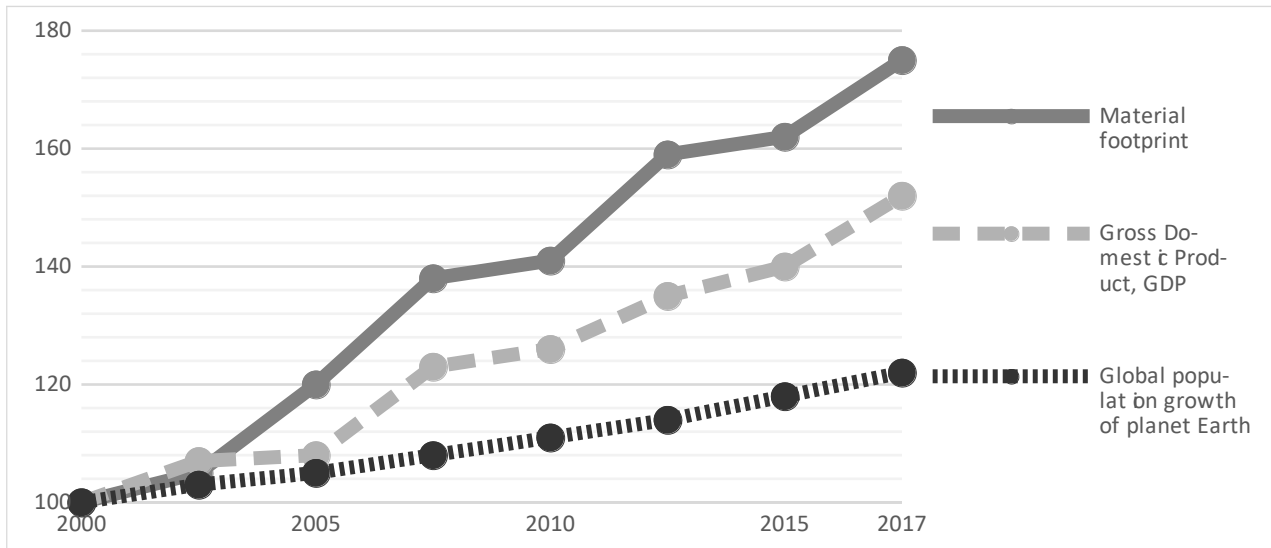

Figure 6. Indices of population growth of the Earth, resource costs and GDP on the planet, 20002017 (base indicator for $2000-100 \%$ ) [8]

In order to meet the needs of one average resident of the planet in 2017, 12.2 metric tons of natural resources were needed (an increase of 50\% compared to 1990). At the same time, the highest resource costs indicator was recorded in developed countries - 27 metric tons per capita, which was $60 \%$ higher than in middle-income economies and more than 13 times for underdeveloped countries.

Achievement of the global Goal of transition to sustainable consumption and production patterns until 2030 is directly dependent on the early implementation of fundamentally new qualitative national and interstate strategic mechanisms to improve resource efficiency, reduce waste, and transition to sustainable management methods in all branches of the economy. The global population increase of the planet and GDP growth must be strongly overcome. The implementation of sustainable production and consumption processes at the global level will not only provide common economic benefits but, no less important, will contribute to the achievement of social benefits, in particular in the field of health, gender relations, support for the poor, social dialogue and the like.

\subsection{Goal 13. Combating climate change}

Permanent climate change on Earth is an objective natural phenomenon. Such changes took place before the emergence of humanity and will continuously occur in the future. According to many environmental scientists, human activity results certainly affect climate change, but this influence is not absolutely decisive in all-natural processes on the planet. 
It is also objectively impossible to achieve such a state that a person does not affect climatic conditions at all, with the modern level of development of civilization. From a methodological point of view, the very formulation of the global Sustainable Development Goal 2030 "13 Climate impacts.

Take urgent action to combat climate change and its impacts" does not fully meet the criteria for the final goal, but rather characterizes the mechanisms for achieving it. But the fight against climate change cannot be considered a self-sufficient function of humanity, but often acts as a positive factor in the sustainable development of industry and agriculture, the rational use of water resources, and the transition to modern energy sources, the implementation of innovations, etc.

As of May 2019, the Paris Agreement has already been ratified by 186 participating countries. It has pledged to make regular contributions in defense of the environment at the national level Nationally Determined Contributions (NDCs) and increase funding for climate change.

The Sendai Framework for Disaster Risk Reduction, 2015-2030 provides precise goals and preferences to prevent new and reduce the current negative effects of natural disasters, the economic losses from which amounted to more than $\$ 3$ trillion, and nearly 1,300,000 human lives during 1998-2017. Globally, volume of financing of combating climate change has increased, the main share of which has been directed at reducing greenhouse gas emissions.

The United Nations Climate Change Secretariat Standing Committee on Finance estimates that total climate finance has grown by $17 \%$ and amounted to $\$ 681$ billion over the past five years, primarily through new private investments in renewable energy. The volume of financial flows that were used for efforts to reduce climate change in developing countries increased by 38\% (more than $\$ 69$ billion USA) during 2015-2016. Many of the developing countries have initiated the process of developing and implementing National Adaptation Plans, which are designed to reduce their sensitivity to climate change and adapt national environmental protection activities to national development strategies.

The number of countries implementing (developing) their own NAPs plans has increased by $45 \%$ since 2015 . Certainly, much is being done to preserve and protect the environment in the world. But climate change is happening at a much faster pace than expected five years later for objective and subjective reasons.

The increase in greenhouse gases in the atmosphere continues. The average world temperature is increasing steadily from year to year, and the oceans' level is rising at an increasing pace. In this context, it is necessary to realize unprecedented in scope and time changes in all spheres of human activity to prevent climate change's catastrophic and adverse effects. To keep global warming within $1.5^{\circ} \mathrm{C}$, to make qualitative changes in such areas of the world economy as: energy, land resources, urban infrastructure and industry as soon as possible, it is necessary to reduce carbon emissions in the air by $45 \%$ (compared to 2010) by 2030, and even achieve net zero emissions into the atmosphere by 2050.

Finally, it is necessary to achieve global investments in climate change-related goals exceeding investments in fossil fuel extraction (the latter amounted to 781 billion dollars in the USA in 2016).

\subsection{Goal 14. Marine ecosystems preservation}

There is no doubt that the oceans have a direct impact not only on our present but also on human civilization's future existence. Exactly ocean provides food and means of living to billions of people, generating almost half of all the oxygen that humanity breathes and acts as a defining regulator of climate, absorbing heat from the atmosphere and neutralizing more than a quarter of anthropogenic $\mathrm{CO} 2$. Preservation and management of oceans, seas 
and marine resources is one of the global Sustainable Development Goals in 2030.

However, the steady growth in global carbon emissions, pollution and degradation of the marine environment has led to an increase in the temperature of sea water and changes in its chemical composition, ocean acidification, overall sea level rise, extreme meteorological events, coastal erosion and the like in recent years. Although water quality has improved slightly over the past six years in 104 of the world's 220 coastal regions, pollution from land, sewage, nutrient flushing, plastic scrap continue to cause widespread coastal eutrophication, deterioration of water quality and degradation of coastal marine ecosystems. Today, the most threatening situation with water purity, as one of the defining indicators of ocean pollution, has developed in some equatorial zones, mainly in several regions of Asia, Africa and Central America. The share of global fish stocks (at the level of biological recovery) decreased from $90 \%$ in 1974 to $67 \%$ in 2015.

The worst indicators of fish resources were recorded in the Mediterranean and the Black Sea regions (37.8\%), as well as in the Southeast Pacific Ocean (38.5\%). Illegal, unregistered and unregulated fishing (IUU fishing), which leads to the depletion of fishing areas, causes their exhaustion, deprives local residents of means of survival and increases poverty, especially in the least developed countries, continues to be prevalent. The achievement of the global Millennium Development Goal on the preservation and management of oceans, seas and marine resources for the sustainable development of humankind until 2030 will require additional efforts by the global community, including the adoption of special national programs aimed at improving access to wastewater treatment infrastructure, reducing the ablation of agricultural chemicals and nutrients and reducing significantly plastic waste. In addition, efforts to establish and develop marine protected areas, as well as national programs and international agreements to support responsible exploitation of marine resources, should be intensified.

\subsection{Goal 15. Protection and restoration of terrestrial ecosystems}

The consequences of human activity continue to cause irreparable harm to the state of the planet's ecosystems, on which all biological species and then the future of civilization depend directly. Although deforestation has generally slowed, the loss of green spaces continues at an alarming rate.

According to the UN, one million species of flora and fauna are in danger of extinction. Over the past 20 years, about $20 \%$ of our planet's total land area has degraded. The rate of global biodiversity loss is increasing, bringing us steadily closer to the line beyond which unpredictable and irreversible changes in ecosystems of the planet will begin. According to The Red List Index, the hazard of the imminent extinction of biological species on the planet has increased by about $10 \%$ over the past 25 years. As figure 7 [9] shows, the negative process of extinction of global biodiversity on the planet has become critical and has a steady tendency to deteriorate over the past thirty years. According to the authoritative IPBES, the biological diversity loss of the Earth is now the fastest in human history. 


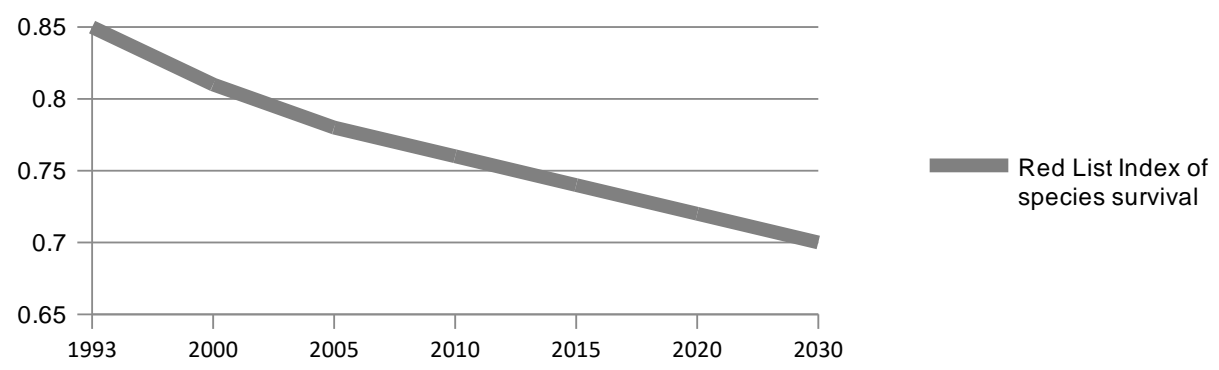

Fig. 7. Red List Index of Species Survival on the Planet (1993-2019) and Forecast to 2030 [9]

According to our forecasts, it is likely that it will not be possible to achieve the planned results in the field of protecting and restoring terrestrial ecosystems and promoting their rational use by 2030 . The restoration of biological diversity on the planet, the really careful management of forests, the real fight against desertification and land degradation requires qualitatively new mechanisms of inter-state cooperation with the participation of all countries in this field, as well as focused integrated programs under the auspices of international environmental organizations.

\subsection{Goal 16. Peace, justice and strong institutions}

Since the launch of the global Sustainable Development Goals in 2015 until 2030, there has not been a radical turning point and a fundamental shift in eradicating violence, promoting the rule of law, strengthening institutions at all levels, and improving real access to justice yet. Millions of people on the planet suffer from attacks on their security, rights and opportunities. Numerous attacks against human rights defenders and journalists continue. A record number of refugees (70 million people) fled from war, persecution, and various regional conflicts in 2018. It is impossible to overcome the global trend of increasing the number of murders, which amounted to more than 6 cases for every 100 thousand people, especially in Latin America and the Caribbean (34\% of all violent crimes with deaths globally) 2018.

The number of victims of trafficking (almost two times), especially among women and girls, for purposes of sexual exploitation (about 59\% of cases) and forced labor (about $30 \%$ of cases) is steadily increasing. The shameful practice of not registering newborns continues, and their fundamental human rights to access basic social services and justice are openly violated. In total, less than $75 \%$ of children under the age of 5 years are registered as of 2018. The critical situation is in sub-Saharan Africa (46 percent of registered children), Central and South Asia, and South-East Asia (68 percent of registered children). According to the UN, since 2015, an average of about 350 human rights defenders, journalists and union members have been killed in the world every year, half of whom have been dealing with community problems on land, environment, poverty, minority and indigenous people rights, as well as the consequences of commercial activities. It is significant that most of the murders of journalists and bloggers were committed in countries where there were no armed conflicts. The analysis suggests that we still have a lot to do on the road to building a peaceful, open society for sustainable development, ensuring common access to justice, and building effective, reporting power institutions.

In this way, one of the effective mechanisms can be the widespread development of a network of National Human Rights Institutions (NHRIs), which have improved significantly the overall situation in the world with respect to the protection of fundamental human rights and freedoms, provided accessible legal assistance and advice (especially for refugees), raised the transparency and legal literacy of the population to a new high level, 
increased opportunities for international cooperation, etc. [10].

\subsection{Goal 17. Partnership for Sustainable Development}

While there are a growing global understanding and public awareness of the need to achieve the global Sustainable Development Goals, many challenges remain. As the analysis shows, many countries have ceased to participate in multilateral programs as a result of the recent deployment of so-called "trade wars" between the world's most economically powerful states and the slowdown in global growth. There is much doubt about the existing global trading system's resilience within the World Trade Organization (WTO).

The overall level of disbursements of official development assistance (ODA) continues to decline steadily, and incoming is often inconsistent with sustainable development priorities. The digital divide between and within countries of the world remains, especially in less developed regions of the world. Thus, net official development assistance decreased by $2.7 \%$ in 2018 , compared to last year, primarily due to donor countries expenditure on the hosting refugees. The volume of humanitarian assistance in the world has generally fallen by $8 \%$ in real form, especially in Africa. The donor countries fail to meet their commitments to increase development financing expenditures and hamper significant efforts to achieve global goals [11].

Personal remittances of migrant workers from abroad have become the largest external source of finance in low- and middle-income economies and amounted to more than 550 billion dollars the USA at the end of 2019. However, recently the positive role of remittances of international migrant workers has been significantly reduced by the massive outflow of workers and the border closures caused by the COVID-19 pandemic, as well as by the relatively high cost of such remittances ( 10 per cent of the transferred amount in Africa and between small islands of the Pacific). Global access to broadband networks, as a driving force for development and as a means of achieving many of the global Sustainable Development Goals, has not yet been achieved. Today, only a little more than half of the earthmen use the Internet (about 4 billion people). Moreover, such people are more than $80 \%$ in developed countries, in developing countries - about $45 \%$, and in the least developed countries - only $20 \%$. Although there has been a steady trend at the global level of broadband subscriber growth (an average of $7 \%$ annually), it's too small quantity to achieve the global Sustainable Development Goals until 2030 [12].

Considering that there is not much time left until 2030, the strengthening and further expansion of international cooperation is crucial to human civilization's sustainable development. Overcoming imbalances in the world economy and making greater use of the domestic resources of all countries of the world based on the principle of national ownership is crucial for achieving the Global Millennium Goals, particularly through the optimization of fiscal policies. An effective revenue administration system is a necessary condition for dynamic, gradual, integrated economic advancement. But countries have to create the components of such system themselves as well as financial support structures taking into account local specifics.

\section{Conclusions}

A critical author's analysis of the achievements towards the global Millennium Goals, which were proclaimed five years later as the "The 2030 Agenda", as a fundamental strategy for the welfare of humankind on a blooming planet, shows that despite some progress in key areas and positive developments in certain areas of life, a fundamental turning point in the widespread implementation of sustainable development has not been 
achieved. Planetary environmental degradation continues, unprecedented levels of greenhouse gas emissions cannot be overcome, ocean acidification increases, coastal erosion and extreme meteorological events spread, devastating natural disasters increase, land degradation occurs, vital biological species disappear, ecosystems collapse and the like.

The problem of hunger is increasing in the world. Basic health care is inaccessible for almost half of the world's population. More than half of the children living on the planet do not know how to read and count. Only 28 per cent of people with severe disabilities receive the allowance, and women in all parts of the world continue to suffer from systemic inequalities as well as discrimination. The worst consequences of these world problems will be for the poor regions and sectors of the world's population. It is quite likely that already in 2050 there will be a widespread shortage of food and 140 million people will be forced to seek sustenance in other countries [13].

It is clear that in order to achieve the fundamental social and economic changes proclaimed by the UN member countries until 2030, the world requires the implementation of a fundamentally new qualitative model of sustainable development management at the regional, national and global levels, especially in such areas of human activity as: effective financing; ensuring resilience; the development of a sustainable and inclusive economy; enhancing the capacity of institutions; regional and local development; more rational use of resources; also bringing together science, technology and innovation through digital transformation.

The new paradigm of governance for sustainable development, in the form of governance for the achievement of the 17 global Millennium Goals, aims to make such strategic decisions that would serve global interests, and efforts of the countries are supported by effective international collaboration through diplomacy and crisis prevention. The only governance mechanism for sustainable development at the global, national and regional levels will enable the implementation of the "The 2030 Agenda" as an integral strategic objective and identify the highest priority areas of joint efforts for targeted measures. Through the implementation of government regulations on sustainable development, it will be possible to identify the linkages between existing problems of human activity more effectively, adopt an integrated approach, and increase significantly investment in combating poverty, inequality, and climate change.

And, importantly, finally establish a unified global data collection system from all countries of the world on indicators of sustainable development (now most countries collect data regularly on only half of global indicators). The methodological justification of the fundamentally new scientific term "sustainable government administration," the disclosure of its essence, the study of features and mechanisms of implementation will be devoted to our further scientific research.

\section{References}

1. The Millennium Project, MP Node, Global Futures Studies \& Research, [Online], [Retrieved May 11, 2020], (2020), http://www.millennium-project.org/about-us

2. United Nations Development Program, [Online], [Retrieved April 08, 2020], (2020), https://www.undp.org/content/undp/en/home/librarypage/corporate/annual-report2019.html

3. The Sustainable Development Goals Report, United Nations publication issued by the Department of Economic and Social Affairs, [Online], [Retrieved May 11, 2020], (2019), https://unstats.un.org/sdgs/report/2019/The-Sustainable-Development-GoalsReport-2019.pdfhttps://unstats.un.org/sdgs/report/2019/The-Sustainable-DevelopmentGoals-Report-2019.pdf 
4. About the 2019 SDG Report, 'Sustainable Development Goals'. UN. [Online], [Retrieved May 12, 2020], (2019), https://www.un.org/sustainabledevelopment/

5. Sustainable Development Report, The UN Sustainable Development Solutions Network (SDSN) 'Transformations to Achieve the Sustainable Development Goals'. [Online].

[Retrieved May 05, 2020],(2019), https://s3.amazonaws.com/sustainabledevelopment.report/2019/2019_sustainable devel opment report.pdf

6. The World Bank DataBank. Database, Poverty and Inequality, [Online]. [Retrieved May 11, 2020], (2014),

http://databank.worldbank.org/data/views/variableselection/selectvariables.aspx? source =poverty-and-inequality-database

7. World Inequality Report, WID.world. The World Inequality Lab, [Online]. [Retrieved May 11, 2020], (2018), https://wir2018.wid.world/

8. EUROSTAT, Compilation guide 2018. Economy-wide material flow accounts, [Online]. [Retrieved May 11, 2020], (2018), https://ec.europa.eu/eurostat/web/products-manuals-and-guidelines/-/KS-GQ-18-006

9. IPBES, The Global Assessment Report on Biodiversity and Ecosystem Services, Intergovernmental Science-Policy Platform on Biodiversity and Ecosystem Services, [Online]. [Retrieved May 06, 2020], (2019), https://ipbes.net/global-assessment

10. The Office of the High Commissioner for Human Rights (UN Human Rights), National Human Rights Institutions, History, Principles, Roles and Responsibilities, [Online]. [Retrieved May 11, 2020], (2020), https://www.ohchr.org/Documents/Publications/PTS-4Rev1-NHRI_en.pdf

11. The World Trade Organization (WTO), World Trade Statistical Review, Documents and resources, [Online]. [Retrieved May 11, 2020], (2019), https://www.wto.org/english/res_e/statis_e/wts2019_e/wts19 toc_e.htm

12. DATAREPORTAL, Digital 2020: 'Global Digital Overview'. [Online]. [Retrieved May 06, 2020], https://datareportal.com/reports/digital-2020-global-digital-overview

13. Liu Zhenmin, Introduction to The Sustainable Development Goals Report, [Online]. [Retrieved May 04, 2020], (2019), https://unstats.un.org/sdgs/report/2019/TheSustainable-Development-Goals-Report-2019.pdf 